МРНТИ 06.52.35

УКД 338.2

\title{
СРАВНИТЕЛЬНЫЙ АНАЛИЗ ГОСУДАРСТВЕННОГО РЕГУЛИРОВАНИЯ СФЕРЫ ЗДРАВООХРАНЕНИЯ РОССИЙСКОЙ ФЕДЕРАЦИИ И РЕСПУБЛИКИ КАЗАХСТАН
}

\author{
С.В. Никифорова \\ Алматинский гуманитарно-экономический университет, Алматы, Казахстан \\ e-mail: nikiforova-s@mail.ru
}

\begin{abstract}
Аннотация. В статье проведен сравнительный анализ государственного регулирования сферы здравоохранения Российской Федерации и Республики Казахстан. Анализ систем здравоохранения показывает общность принципов организации государственной сочиальной политики в области охраны здоровья граждан. Это объясняется и историческими корнями советского прошлого, единым технологическим укладом и сотрудничеством в сфере развития. Деятельность сферы здравоохранения двух стран (России и Казахстана) очень родственны, и построены на принципах ВОЗ, где основным приоритетом является - здоровье начии.

Проанализированы показатели расходов на здравоохранение России и Казахстана, основные сочиально-демографические показатели. Выявлены общие для двух стран ориентиры дальнейшего развития системы здравоохранения. Основные из них: развитие системы добровольного медичинского страхования; чифровизачия здравоохранения; привлечение квалифичированных кадров; поддержание тренда активного и взаимовыгодного сотрудничества с неправительственными организачиями.
\end{abstract}

Ключевье слова: сфера здравоохранения, государственная поддержка, охрана здоровья, расходы на здравоохранение.

Основные положения. Рынок медицинских услуг имеет ограниченную эффективность. Для него характерны такие явления как неполнота оказываемых услуг (доступность для всех нуждающихся), асимметрия информации (особенно отдаленные районы), высокие издержки и неэффективная цена. Государство берет на себя обязанности по организации и распределения медицинских услуг путем перераспределения экономических ресурсов.

Введение. Система здравоохранения обеспечивает реализацию государственной политики в области охраны здоровья населения и вопросы здоровья нации актуальны во всем мире. Цель настоящего исследования - провести сравнительный анализ государственного регулирования сферы здравоохранения Российской Федерации и Республики Казахстан.

Методы. Методологической основой исследования являются такие методы, как анализ и синтез, сравнение, логический подход к изучаемым проблемам.

Результаты. Законодательство Российской Федерации в сфере охраны здоровья основывается на Конституции Российской Федерации, Федеральном законе «Об основах охраны здоровья граждан РФ» и иных нормативно-правовых актах. Основной принцип государственной плитки в сфере здравоохранения - соблюдение прав граждан в сфере охраны здоровья и обеспечение связанных с этими правами государственных 


\section{(ㅅ)}

гарантий. Система здравоохранения основывается на государственной, муниципальной и частной собственности [1].

Государственная система образована федеральными органами исполнительной власти в сфере охраны здоровья, исполнительными органами государственной власти субъектов РФ и подведомственными организациями. Муниципальная система здравоохранения состоит из органов местного самоуправления муниципальных районов и городских округов, подведомственных организаций. Частная система здравоохранения состоит из юридических медицинских, фармацевтических и иных организаций и физических лиц, осуществляющих медицинскую деятельность. Федеральным органом исполнительной власти в области охраны здоровья граждан РФ является Министерство здравоохранения.

Организация охраны здоровья граждан РФ осуществляется: путем государственного и нормативного регулирования и управления сферой охраны здоровья; разработка и проведение профилактических мероприятий по возникновению и распространению заболеваний; организация оказания всех видов медицинской помощи; обеспечение санитарно-эпидемиологического благополучия населения; обеспечение лекарственными средствами и медицинскими изделиями определенной категории граждан.

Основными источниками финансирования сферы охраны здоровья являются Федеральный бюджет, бюджеты субъектов РФ, муниципальных районов и городских округов; средства Фонда обязательного медицинского страхования; целевые фонды и государственный внебюджетные фонды; доходы организаций здравоохранения и другие источники.

Приоритеты расходования средств вытекают из состояния анализа здоровья населения страны. В первую очередь, это расходы: на создание условий доступности медицинской помощи; расширение категорий населения, которым компенсируются расходы на лечение; повышение заработной платы работникам сферы здравоохранения, в особенности первичного звена; развитие стационарных отделений скорой медицинской помощи; информатизация здравоохранения; повышение квалификации медицинского персонала и др.

Анализируя данные таблицы 1 , можно отметить, что расходы на здравоохранение в России сегодня составляют $7,09 \%$ от ВВП.

Основные направления государственной политики по решению проблем в сфере здравоохранения и определение основных приоритетов развития, отражены в Федеральной Государственной программе Российской Федерации «Развитие здравоохранения». Основная цель программы - снижение смертности в Российской Федерации и увеличение продолжительности жизни.

Таблиия 1

Расходын на здравоохранение в Российской Федераџии

\begin{tabular}{|l|c|c|c|c|c|c|}
\hline & $2000 г$. & $2004 \Gamma$. & $2008 г$. & $2012 г$. & $2016 г$. & 2019 г. \\
\hline В \% от ВВП & 5,42 & 5,19 & 6,22 & 6,88 & 7,07 & 7,09 \\
\hline $\begin{array}{l}\text { В долларах США на душу } \\
\text { населения по Паритету по- } \\
\text { купательской способности }\end{array}$ & 171,8 & 259,4 & 452 & 739,5 & 883 & 916,5 \\
\hline
\end{tabular}

Составлено автором по источнику [2] 
В программе определены 8 основных приоритетов развития, которые на сегодняшний день являются слабыми местами в современной российской системе здравоохранения: развитие системы оказания первичной медико-санитарной помощи; борьба с сердечно-сосудистыми заболеваниями; борьба с онкологическими заболеваниями; развитие детского здравоохранения; развитие сети национальных медицинских исследовательских центров и внедрение инновационных технологий; создание единого цифрового пространства в сфере здравоохранения; развитие экспорта медицинских услуг [3].

Отдельно стоит вопрос обеспечение медицины современными квалифицированными кадрами и создание механизмов мотивации. Низкий уровень заработной платы в государственном секторе вызывают острый дефицит кадров. На сегодняшний день политика государства по решению этой проблемы строится на обеспечении условий и стимулов, таких как: расширение доступности образования путем создания большего количества бюджетных мест; внедрения новых систем и форм оплаты труда; реформирование системы первичной медико-санитарной помощи; расширение государственночастное партнерство. Несмотря на то, что это пока точечные проекты, уже понятно, что существуют возможности использования частных ресурсов для выполнения традиционно государственных задач, в связи с чем, происходит поиск наиболее приемлемых форм и моделей сотрудничества.

Государственное регулирование в области здравоохранения в Республике Казахстан осуществляют Президент РК, Правительство РК, Министерство здравоохранения РК и центральные и местные исполнительные органы. Правовое регулирование системы здравоохранения РК основывается на Конституции РК, Кодексе РК «О здоровье народа и системе здравоохранения», Законах РК, Государственной программе развития здравоохранения «Денсаулык» и иных актах.

Система здравоохранения состоит их государственного и негосударственного секторов здравоохранения, которые представляют собой организации здравоохранения, научные и образовательные организации, основанные на праве государственной или частной собственности.

Государственное регулирование осуществляется путем проведения государственного контроля за медицинской и фармацевтической деятельностью, а также санитарно-эпидемиологического надзора; лицензирования деятельности; аккредитации и аттестации; государственной регистрации лекарственных средств и медицинской техники; регулирования цен на лекарственные препараты и медицинские услуги в рамках гарантированного объема бесплатной медицинской помощи. Основной принцип государственной политики РК в области здравоохранения - отнесение здоровья населения к факторам обеспечения национальной безопасности [4].

Основными источниками финансирования затрат на систему здравоохранения в стране являются средства республиканского и местных бюджетов, средства Фонда обязательного медицинского страхования.

Расходы на здравоохранение в Казахстане составляют 3,7\% от ВВП, что практически в два раза ниже, чем в Российской Федерации (табл.2). Так же существенно ниже эти расходы и в расчете на душу населения.

Основные направления финансирования: формирование государственной политики в области здравоохранения; подготовка специалистов в организациях высшего, технического и профессионального, послесреднего образования и социальная поддержка обучающихся; повышение квалификации и переподготовка кадров; прикладные научные исследования; реформирование системы здравоохранения и развитие инфра- 


\begin{tabular}{|c|c|c|c|c|c|c|}
\hline \multicolumn{7}{|c|}{$\begin{array}{l}\text { структуры; социальное медицинское страхование; оказание } \\
\text { мощи в рамках обязательного медицинского страхования и } \\
\text { печение гарантированного объема бесплатной медицинской п } \\
\text { Таблица } 2 \\
\text { Расходы на здравоохранение в Республике Казахстан }\end{array}$} \\
\hline & $2000 \Gamma$. & $2004 \Gamma$ & $2008 \Gamma$ & $2012 \Gamma$. & 2016г. & 2019г. \\
\hline В \% от ВВП & 4,16 & 3,61 & 3,95 & 3,73 & 3,65 & 3,7 \\
\hline $\begin{array}{l}\text { В долларах США на душу } \\
\text { населения по Паритету по- } \\
\text { купательской способности }\end{array}$ & 119,94 & 177,21 & 219,99 & 257,47 & 311,84 & 544 \\
\hline
\end{tabular}

Составлено автором по источнику [5]

Государственное устройство в Казахстане проще, чем в Российской Федерации, т.к. отсутствует деление на территориальные округа и муниципальные образования. Вертикаль распределения экономических ресурсов более централизована: высшие органы государственной власти - местные органы государственной власти. Горизонтальное распределение ресурсов также основывается на дотациях и субсидиях между местными органами государственной власти.

По мнению аналитиков Национальной палаты предпринимателей РК основными провалами рынка с точки зрения эффективности в Казахстане являются недостаточный уровень грамотности и информированности населения о вреде потребления алкоголя, курения, несбалансированного питания; не достаточный уровень заработной платы медицинских работников государственного сектора, дисбаланс кадров и неоднородный уровень сервиса и качества медицинской помощи; устаревающая инфраструктура [6].

Особенно остро наблюдаются кадровые проблемы. В первую очередь это касается квалифицированных кадров в области среднего и младшего медицинского персонала. Существующую проблему порождает малое количество учебных заведений соответствующего уровня и ежегодный массовый отток выпускников школ в зарубежные учебные заведения.

Также отдельным вопросом стоит уровень оплаты труда, который снижает мотивационный фактор. В силу низкого уровня заработной платы происходит большой перелив высококвалифицированных специалистов в частный сектор, оказывающий только платные услуги, что порождает недоступность качественного медицинского обслуживания для широких слоев населения.

Для решения этих проблем на сегодняшний день разработана Государственная программа развития здравоохранения Республики Казахстан на 2020-2025гг. В программе определены следующие направления государственной политики: полная цифровизация здравоохранения; создание мобильных и веб-приложений для информирования и вовлечения населения в охрану собственного здоровья; формирование городской среды, благоприятствующей поддержанию здорового образа жизни; повышение уровня грамотности и осведомленности населения по вопросам формирования здорового образа жизни, профилактики поведенческих факторов риска, здорового питания; развитие персонифицированной медицины; развитие медицинского туризма; государственночастное партнерство в здравоохранении; внедрение обязательного социального медицинского страхования [7]. 
Из приведенного обзора видно, что системы здравоохранения двух стран (России и Казахстана) очень родственны. Это объясняется и историческими корнями советского прошлого, единым технологическим укладом и сотрудничеством в сфере развития.

Не смотря на большую разницу в численности населения (население России превышает численности населения Казахстана в 10 раз) есть определенная общность и в социально-экономических показателях (Таблица 3 ).

\section{Таблий 3}

Основные сочиально-демографические показатели:

\begin{tabular}{|c|c|c|c|c|c|c|c|c|c|c|}
\hline & 2000 & 2002 & 2005 & 2007 & 2009 & 2011 & 2013 & 2015 & 2017 & 2019 \\
\hline \multicolumn{11}{|c|}{ Ожидаемая продолжительность жизни населения при рождении, лет } \\
\hline $\begin{array}{l}\text { Российская } \\
\text { Федерация }\end{array}$ & 65,34 & $64,95 \uparrow$ & $65,31 \uparrow$ & $66,69 \uparrow$ & $67,99 \uparrow$ & $68,94 \uparrow$ & $70,24 \uparrow$ & $70,93 \uparrow$ & $71,87 \uparrow$ & $72,91 \uparrow$ \\
\hline $\begin{array}{l}\text { Республика } \\
\text { Казахстан }\end{array}$ & 65,45 & $65,95 \uparrow$ & $66,06 \uparrow$ & $66,15 \uparrow$ & $67,11 \uparrow$ & $68,45 \uparrow$ & $69,52 \uparrow$ & $71,44 \uparrow$ & $72,41 \uparrow$ & $73,15 \uparrow$ \\
\hline \multicolumn{11}{|c|}{ Общий коэффициент рождаемости (на 1000 человек) } \\
\hline $\begin{array}{l}\text { Российская } \\
\text { Федерация }\end{array}$ & 8,70 & $9,70 \uparrow$ & $10,40 \uparrow$ & $10,30 \downarrow$ & $12,00 \uparrow$ & $12,50 \uparrow$ & $13,30 \uparrow$ & 13,30 & $12,9 \downarrow$ & $10,9 \downarrow$ \\
\hline $\begin{array}{l}\text { Республика } \\
\text { Казахстан }\end{array}$ & 14,92 & $15,29 \uparrow$ & $18,19 \uparrow$ & $19,71 \uparrow$ & $22,60 \uparrow$ & $22,53 \downarrow$ & $22,70 \uparrow$ & $23,10 \uparrow$ & 22,52 & $21,77 \downarrow$ \\
\hline \multicolumn{11}{|c|}{ Общий коэффициент смертности (на 1000 человек) } \\
\hline $\begin{array}{l}\text { Российская } \\
\text { Федерация }\end{array}$ & 15,30 & $16,20 \uparrow$ & $15,90 \downarrow$ & $15,10 \downarrow$ & $14,50 \downarrow$ & $14,20 \downarrow$ & $13,30 \downarrow$ & $13,10 \downarrow$ & $12,9 \downarrow$ & $12,5 \downarrow$ \\
\hline $\begin{array}{l}\text { Республика } \\
\text { Казахстан } \\
\end{array}$ & 10,06 & $10,05 \downarrow$ & $10,14 \uparrow$ & $10,27 \uparrow$ & $9,74 \downarrow$ & $8,95 \downarrow$ & $8,54 \downarrow$ & $7,65 \downarrow$ & 7,37 & $7,14 \downarrow$ \\
\hline \multicolumn{11}{|c|}{ Коэффициент младенческой смертности (на 1000 родившихся) } \\
\hline $\begin{array}{l}\text { Российская } \\
\text { Федерация }\end{array}$ & 15,30 & $13,30 \downarrow$ & $11,60 \downarrow$ & $10,20 \downarrow$ & $8,50 \downarrow$ & $7,50 \downarrow$ & $8,60 \uparrow$ & $7,40 \downarrow$ & $6 \downarrow$ & $5,1 \downarrow$ \\
\hline $\begin{array}{l}\text { Республика } \\
\text { Казахстан }\end{array}$ & 18,80 & $17,00 \downarrow$ & $14,50 \downarrow$ & $13,91 \downarrow$ & $20,76 \uparrow$ & $16,59 \downarrow$ & $13,56 \downarrow$ & $9,83 \downarrow$ & $8,59 \downarrow$ & $8,03 \downarrow$ \\
\hline \multicolumn{11}{|c|}{ Естественный прирост населения на 1000 человек } \\
\hline $\begin{array}{l}\text { Российская } \\
\text { Федерация }\end{array}$ & $-6,6$ & $-6,5 \uparrow$ & $-5,5 \uparrow$ & $-4,8 \uparrow$ & $-2,5 \uparrow$ & $-1,7 \uparrow$ & $0,0 \uparrow$ & $0,2 \uparrow$ & $-0,01 \downarrow$ & $-1,6 \downarrow$ \\
\hline $\begin{array}{l}\text { Республика } \\
\text { Казахстан }\end{array}$ & 4,86 & $5,24 \uparrow$ & $8,05 \uparrow$ & $9,44 \uparrow$ & $13,01 \uparrow$ & $13,58 \uparrow$ & $14,16 \uparrow$ & $15,45 \uparrow$ & $15,14 \downarrow$ & $14,63 \downarrow$ \\
\hline
\end{tabular}

Составлено автором по источнику [8,9]

В условиях глобализации экономики, влияние экономических кризисов, сказывается на демографических провалах всех стран. Так, можно наблюдать тенденцию снижения рождаемости и соответственно снижение естественного прироста населения. Однако остальные показатели показывают оптимистичные результаты. Можно отметить стабильную тенденцию увеличения ожидаемой продолжительности жизни. В среднем за исследуемый период она увеличилась на 7-8 лет. Стабильную тенденцию к снижению показывает показатель общего коэффициента смертности (в среднем снижение на 3\%). Очень значительно снижение детской смертности - на $10 \%$ в каждой стране. 
Заключение. Проведя анализ систем здравоохранения двух стран можно отметить общность принципов организации государственной социальной политики в области охраны здоровья граждан. Деятельность сферы здравоохранения построена на принципах ВО3, где основным приоритетом является - здоровье нации. В связи с чем, можно отметить общие для двух стран ориентиры дальнейшего развития системы здравоохранения:

- переориентация переориентации медицинских услуг на профилактику, раннее выявление болезней и эффективное управление болезнями согласно нуждам и потребностям людей в получении своевременной и качественной медицинской помощи;

- формирование сильной, устойчивой первичной медико-санитарной помощи;

- активное развитие системы добровольного медицинского страхования;

- цифровизация здравоохранения, обеспечение доступа к более полноценной информации о пациенте для принятия правильного решения о лечении и лучшей координации медицинской помощи;

- развитие всех уровней оказания медицинской помощи, клинических служб и всех этапов оказания медицинской помощи, включая паллиативную, реабилитационную помощь и уход на дому;

- привлечение квалифицированных кадров в регионы благодаря мерам, принимаемым местными исполнительными органами, позволит снизить дисбаланс кадровых ресурсов здравоохранения, повысить доступность и качество медицинской помощи в регионах, включая географически труднодоступные районы и сельскую местность;

- поддержание тренда активного и взаимовыгодного сотрудничества с неправительственными организациями, представляющими интересы медицинских специалистов, медицинских организаций и пациентов, с целью обеспечения качественной реализации проектов и программ в здравоохранении.

\section{Список литературы}

1. Федеральный закон (далее Ф3) от 21.11.2011 г. № 323-Ф3 «Об основах охраны здоровья граждан Российской Федерации»

2. Официальный сайт Министерства здравоохранения Российской Федерации. Режим доступа: https://www.rosminzdrav.ru/ministry (дата обращения 30.08.2021)

3. Государственная программа Российской Федерации «Развитие здравоохранения». Режим доступа: https://www.rosminzdrav.ru/ministry/programms (дата обращения 30.08.2021)

4. Кодекс Республики Казахстан от 18 сентября 2009 года № 193-IV «О здоровье народа и системе здравоохранения»

5. Официальный сайт Министерства здравоохранения Республики Казахстан. Режим доступа: http://dsm.gov.kz/ru/kategorii/byudzhet-ministerstva (дата обращения 30.08.2021)

6. Экспертное заключение Национальной палаты предпринимателей РК «Атамекен». Режим доступа: http://dsm.gov.kz/ru/pages/obsuzhdenie-gosudarstvennoyprogrammy (дата обращения 30.08.2021)

7. Государственная программа развития здравоохранения Республики Казахстан на 2020-2025 гг. Источник: Официальный сайт министерства здравоохранения Республики Казахстан. Режим доступа: http://dsm.gov.kz/ru/kategorii/byudzhet-ministerstva (дата обращения 30.08.2021) 
8. Официальный сайт Федеральной службы государственной статистики РФ. Режим доступа: https://www.gks.ru (дата обращения 30.08.2021)

9. Официальный сайт комитета по статистике Министерства национальной экономики РК. Режим доступа: http://stat.gov.kz (дата обращения 30.08.2021)

\section{Spisok literatury}

1. Federalnyi zakon (dalee FZ) ot 21.11.2011 g. № 323-FZ «Ob osnovakh okhrany zdorovya grazhdan Rossiiskoi Federatsii»

2. Ofitsialnyi sait Ministerstva zdravookhraneniya Rossiiskoi Federatsii. Rezhim dostupa: https://www.rosminzdrav.ru/ministry (data obrashcheniya 30.08.2021)

3. Gosudarstvennaya programma Rossiiskoi Federatsii «Razvitie zdravookhraneniya». Rezhim dostupa: https://www.rosminzdrav.ru/ministry/programms (data obrashcheniya 30.08.2021)

4. Kodeks Respubliki Kazakhstan ot 18 sentyabrya 2009 goda № 193-IV «O zdorove naroda i sisteme zdravookhraneniya»

5. Ofitsialnyi sait Ministerstva zdravookhraneniya Respubliki Kazakhstan. Rezhim dostupa: http://dsm.gov.kz/ru/kategorii/byudzhet-ministerstva (data obrashcheniya 30.08.2021)

6. Ekspertnoe zaklyuchenie Natsionalnoi palaty predprinimatelei RK «Atameken». Rezhim dostupa: http://dsm.gov.kz/ru/pages/obsuzhdenie-gosudarstvennoy-programmy (data obrashcheniya 30.08.2021)

7. Gosudarstvennaya programma razvitiya zdravookhraneniya Respubliki Kazakhstan na 2020-2025 gg. Istochnik: Ofitsialnyi sait ministerstva zdravookhraneniya Respubliki Kazakhstan. Rezhim dostupa: http://dsm.gov.kz/ru/kategorii/byudzhet-ministerstva (data obrashcheniya 30.08.2021)

8. Ofitsialnyi sait Federalnoi sluzhby gosudarstvennoi statistiki RF. Rezhim dostupa: https://www.gks.ru (data obrashcheniya 30.08.2021)

9. Ofitsialnyi sait komiteta po statistike Ministerstva natsionalnoi ekonomiki RK. Rezhim dostupa: http://stat.gov.kz (data obrashcheniya 30.08.2021)

\section{РЕСЕЙ ФЕДЕРАЦИЯСЫ МЕН ҚАЗАҚСТАН РЕСПУБЛИКАСЫНЫН ДЕНСАУЛЫК САҚТАУ САЛАСЫН МЕМЛЕКЕТТІК РЕТТЕУДІ САЛЫСТЫРМАЛЫ ТАЛДАУ}

\section{С.В. Никифорова \\ Алматы гуманитарль-экономикалық университеті, Алматы, Қазақстан e-mail: nikiforova-s@mail.ru}

Түйін. Мақалада Ресей Федерациясы мен Қазақстан Республикасының Денсаульққ сақтау саласын мемлекеттік реттеуге салыстырмалы талдау жүргізілді. Денсаульққ сақтау шызыстарының көрсеткіштері, негізгі әлеуметтік-демографияльққ көрсеткіштер талданды. Талдау азаматтардың денсаулывын сақтау саласындавы мемлекеттік әлеуметтік саясатты ұйымдастыру қавидаттарының ортақтывын көрсетеді. Денсаулық сақтау жүйесін одан әрі дамытудыџ екі елге ортақ бавдары анықталды.

Түйінді сөздер: Денсаулық сақтау саласы, мемлекеттік қолдау, денсаулывынн қорвау, денсаулық сақтау шывындары. 


\title{
COMPARATIVE ANALYSIS OF THE STATE REGULATION OF THE HEALTHCARE SECTOR OF THE RUSSIAN FEDERATION AND THE REPUBLIC OF KAZAKHSTAN
}

\author{
С.В. Никифорова \\ Almaty University of Humanities and Economics, Almaty, Kazakhstan \\ e-mail: nikiforova-s@mail.ru
}

Summary. The article presents a comparative analysis of the state regulation of the healthcare sector of the Russian Federation and the Republic of Kazakhstan. The indicators of healthcare expenditures in Russia and Kazakhstan, the main socio-demographic indicators are analyzed. The analysis of health care systems shows the commonality of the principles of the organization of state social policy in the field of public health protection. The guidelines for the further development of the healthcare system that are common for the two countries are identified.

Key words: healthcare sector, state support, health protection, health care costs.

ГРНТИ 06.61.53

УДК 332.711 https://doi.org/10.51579/1563-2415.2021-3.06

\section{ПРИНЦИПЫ И КОНЦЕПЦИИ СОВРЕМЕННОГО УРБАНИЗМА}

\author{
* Г.Ж.Сейтхамзина, Л.М.Бекенова, Э.Х.Ахатова \\ Алматинский гуманитарно-экономический университет, Алматы. Казахстан \\ e-mail: gau17erj@mail.ru
}

Аннотация. Целью статьи является их систематизация и анализ, а также выявление универсальных для современного глобального общества моделей и стратегий развития и модернизации городов. Для проведения комплексного и глубокого анализа современных урбанистических конщепчий и их систематизации, авторы исследуют само понятие урбанизачии, и основные принџипь и конщепџии современного урбанизма. Изучены основные аспекты проявления глобальности урбанизации на современном этапе, философско-мировоззренческие, проблемные и пространственные (географические). А также даны основные положения градострочтельства, разработанные в рамках концепџии Нового урбанизма. После анализа рассмотренных основных положений сделан вывод, что данная конщепция направлена на создание комфортных экологически, эргономически и сочиально сбалансированных условий для прожсивания человека и для сохранения природы. При изучении основных конщепџий урбанизации применялся комплекс следующих методов экономических исследований: монографический, программно-иелевой, логический. В работе над исследованием также были использованы такие теоретические методы исследования как, сравнения и обобщения, научная абстракиия и синтез.

Ключевые слова: урбанизачия, современный урбанизм, город, агломерачия, городские поселения, рост городского населения, показатели урбанизированности, урбанистические концепџии. 